\title{
Inflation Metaphor in Contemporary American English
}

\author{
Chunyu $\mathrm{Hu}^{1} \&$ Zhi Chen ${ }^{1}$ \\ ${ }^{1}$ School of English for International Business, Guangdong University of Foreign Studies, Guangzhou, China \\ Correspondence: Chunyu Hu, Associate Professor of School of English for International Business, Guangdong \\ University of Foreign Studies, Guangzhou 510420, China. Tel: 86-203-631-7183. E-mail: gwhcy@gdufs.edu.cn
}

Received: August 3, 2015

Accepted: October 30, 2015

Online Published: November 15, 2015

doi:10.5539/hes.v5n6p21

URL: http://dx.doi.org/10.5539/hes.v5n6p21

\begin{abstract}
Inflation is often regarded as a dangerous phenomenon which poses a potential threat to economies in the world. It is thus an entity that demands the constant attention of economists, policymakers and the general public. In order to make this abstract entry more concrete and vivid, a number of metaphorical expressions are used to depict inflation. Building on previous studies that relied on researchers' intuition or a small corpus, this paper sets out to investigate the use of inflation metaphor by examining a 450-million-word Corpus of Contemporary American English (COCA). The results show that there exist a considerable number of metaphorical collocates of inflation, which can be grouped into separate yet closely related categories: INFLATION IS FIRE, INFLATION IS DISEASE, INFLATION IS AN ANIMAL, INFLATION IS AN ENEMY, INFLATION IS A RACER, INFLATION IS A MACHINE, and the like. This study shows how these metaphors function in specific contexts, and how they structure and reframe our thinking about inflation and other related economic concepts. These findings have pedagogical implications for both teaching of economics and second language learning of relevant words and phrases.
\end{abstract}

Keywords: inflation, COCA, collocation, conceptual metaphors, metaphorical expressions, metaphor network

\section{Introduction}

The phenomenon of metaphor has fascinated scholars for over two millennia. One of the earliest studies can be found in the classical works On Poetics (Aristotle, 2002) and On Rhetoric (Aristotle, 2007) in which metaphor was regarded as an implicit comparison, based on rules of analogy. Despite a considerable effort and endeavor in this special area of human inquiry, it is the advances in philosophy, linguistics and cognitive science over the past three decades that have led to substantial insights into the significance and workings of metaphors.

Of a few influential works, Lakoff and Johnson's (1980) Metaphor We Live By is of paramount importance. This book builds a strong case for the ubiquity and importance of metaphors, arguing that metaphors shape our understanding of the world and our action in it, and that our ordinary conceptual system is fundamentally metaphorical in nature (Lakoff \& Johnson, 1980). Within this cognitive linguistic perspective, the essence of metaphor is regarded as "understanding and experiencing one kind of thing in terms of another" (Lakoff \& Johnson, 1980). It can usually be described with a formula TARGET DOMAIN IS SOURCE DOMAIN (Lakoff, 1993). The conceptual metaphor theory draws a distinction between metaphorical concepts and metaphorical expressions. Conceptual metaphors are mental mappings from a (typically concrete) source domain to a (typically abstract) target domain, while metaphorical expressions are individual linguistic items instantiating these mappings. For example, the conceptual metaphor LIFE IS JOURNEY can by instantiated by We're at a crossroads, We'll just have to go our separate ways, We can't turn back now, and many other metaphorical expressions (Kövecses, 2002).

Clearly, an important function of metaphor is to help people comprehend complex and abstract concepts by mapping onto them the image schemata of simple and concrete ones. In a discipline as abstract as economics, it is expected that metaphorical conceptualization is not an uncommon phenomenon. As a matter of fact, there has been a growing literature on the economic metaphors since 1980s. The original study could be traced back to Henderson (1982) and Jeffreys (1982), whose works have inspired the economist McCloskey. In The Rhetoric of Economics, McCloskey (1985) completely rejects the positivist approach in economics, or what she calls scientism. She maintains that economists, despite their emphasis on mathematical models and statistical techniques, actually rely on human reasoning to communicate their ideas and propose a range of rhetorical 
devices (e.g., metaphor, analogy and appeals to authority) from the literary tradition used for this purpose. The publication of McCloskey's work (McCloskey, 1983, 1985, 1990) brings about "the opportunity for common ground between economists and linguists" (Henderson \& Dudley-Evans, 1990), and has stimulated considerable interest in economic or economics metaphor (Alejo, 2010; Boers, 2000; Charteris-Black, 2000; harteris-Black \& Ennis, 2001; Charteris-Black \& Musolff, 2003; Chung, 2008; Fukuda, 2009; Henderson, 1994, 2000; Hu, 2014; Klamer \& McClosky, 1994; Samuels, 1990; Semino, 2002; Smith, 1995; White, 2003; Resche, 2012).

As an important phenomenon, inflation generally demands the constant attention of experts in economic issues as well as that of the general public. In the meanwhile, inflation as a rather abstract and difficult-to-understand economic phenomenon is often interpreted in terms of more concrete entities. Below is an example from a famous economics textbook in which inflation is considered as a vehicle out of control:

(1) If output is growing rapidly and inflation is rising, the Federal Reserve Board is likely to raise interest rates as this puts a brake on the economy and reduces price pressures (Samuelson \& Nordhaus, 2010).

This paper thus aims to research inflation metaphor by using authentic data from a 450-million-word Corpus of Contemporary American English (COCA), and then discuss how a variety of metaphors can be connected to a coherent network.

\section{Previous Studies on Inflation Metaphor}

According to Oxford English Dictionary (OED), the word inflation derived from the Latin verb inflare, of which in is the prefix and flare means "to blow". It first appeared in English in 1340 as attested in It purges pe longes of inflacioun. From the literal meaning "The action of inflating or distending with air or gas" two metaphorical usages were developed: 1) The condition of being puffed up with vanity, pride, or baseless notions, and 2) "Great or undue expansion or enlargement; increase beyond proper limits; esp. of prices, the issue of paper money, etc. spec. An undue increase in the quantity of money in relation to the goods available for purchase; (in lay use) an inordinate rise in prices".

To our knowledge, Lakoff and Johnson (1980) is the first to conduct a systematic study on inflation metaphor. They claim that we learn to refer to physical entities and only later we refer to abstract concepts such as inflation. Inflation metaphor thus belongs to the class of entity and substance metaphors, also known as ontological metaphors, which is connected with our experiences with physical objects, including our bodies (Lakoff \& Johnson, 1980). The most common case of ontological metaphors is related to the perception of ideas, events, emotions and activities as substances, or concrete entities. INFLATION IS AN ENTITY is one type of ontological metaphor that can be instantiated by a number of metaphorical expressions, as demonstrated below:

(2) INFLATION IS AN ENTITY (Lakoff \& Johnson, 1980)

a. Inflation is lowering our standard of living.

b. If there's much more inflation, we'll never survive. We need to combat inflation.

c. Inflation is hacking us into a corner.

d. Inflation is taking its toll at the checkout counter and the gas pump.

e. Buying land is the best way of dealing with inflation.

f. Inflation makes me sick.

Lakoff and Johnson argued that viewing inflation as an entity enables its quantification, the identification of its particular aspects, seeing it as a cause, and even believing that we understand it. The INFLATION IS AN ENTITY metaphor is "necessary for even attempting to deal rationally with our experiences" (Lakoff \& Johnson, 1980).

Building on Lakoff and Johnson's (1980) original research, Silaski and Durovic (2010) focused on the INFLATION IS A FEROCIOUS ANIMAL metaphor, in which the most salient properties associated with wild animals (the ways they look, eat, behave, sound, attack, as well as the ways they are tamed, controlled, caught or killed) are mapped onto the target domain, INFLATION. In order to collect authentic data, they conducted a Google search in which the query was inflation beast, combined with a small number of words referring to the salient features of animals, mainly verbs which describe the ways animals move (e.g., gallop, crawl, trot, hack, etc.), eat (gobble, devour, etc.), look (e.g., jaws, claws, etc.) and sound (howl, bellow, bark, growl, etc.). The texts obtained in this way were extracted and compiled in one Word file, totaling around 65,000 words. Using such a small corpus Silaski and Durovic (2010) identified six types of the INFLATION IS A FEROCIOUS ANIMAL metaphor, as exemplified in (3): 


\section{(3) INFLATION IS A FEROCIOUS ANIMAL}

a. Inflation in construction is galloping at $1.5 \%$ per month. (the ways animals move)

b. Inflation flashes its sharp teeth against the back drop of dark clouds of recession. (the ways animals look)

c. Inflation roars back in Venezuela in April. (the ways animals sound)

d. Inflation Gnaws At Pet Food Companies. (the ways animals eat/be fed)

e. How to protect your money from this predatory inflation? (the ways animals attack)

f. Korea to double efforts to tame inflation. (the ways animals are controlled)

Another study on inflation metaphor is diachronic by nature. As one of the emerging markets, the growth of Brazilian economy has been accompanied by serious economic problems over the last half century (1960-2010), the most persistent of which being inflation. Berber Sardinha (2012) look at 50 years of metaphors that have been used to refer to the Brazilian economy, particularly to inflation, as well as at the different ways several administrations have tried to defeat it. A range of different sources (from president speeches to magazine reports to electronic corpora) have been consulted to serve as data for his investigation. The result indicates that the last half century of Brazilian economics has been dominated "by the struggle to defeat inflation". The economic plans of that struggle were systematically conceptualized and linguistically expressed by a series of framing metaphors.

Berber Sardinha first unveils the different economic plans Brazil has experienced through a range of metaphors characterizing them and then checks the collocations these plans are associated with in two corpora. To make plans enacted during the military regime more easily understandable to the public, policy makers resort to religion, wealth as a cake, and salary reduction as a rope-tightening stick. Dissatisfaction at the null effect of these policies and persistent rampant inflation spawn a very wide range of metaphors throughout the different plans with, amongst others, inflation seen as a beast, a war, a disease and even as poison. As an antidote to these destructive metaphors, plans first attempt to explain the economy in terms of commonsense, as cooking a simple recipe or as a simple everyday task. As the economic situation becomes dramatic, politicians ask for more desperate efforts in terms of the classic war-time metonymies of Churchill: "sweat" and "sacrifice" are called on to ward off the greater evil of "blood" and "tears". Equally, build metaphors as the desirable stand against the destructive metaphor of fire. Finger-pointing at store owners and underperforming civil servants and calling on the populace to be vigilant license a host of metaphors: e.g., the population is a police force, store managers are thieves, an idle high earning public servant is a maharajah (kings, princes or rulers in India), among others. When inflation is finally brought to book under Fernando Henrique Cardoso and the ensuing period of Lula da Silva, new metaphors appear to grasp and get across the new situation: government as nurturant parent, the country as a family. The essential role of these metaphors in the last half-century of Brazil's economic history allow the author to conclude that it would be "hard to imagine such large-scale initiatives becoming popular or even plausible without major framing metaphors accompanying them" (Berber Sardinha, 2012).

\section{Method}

\subsection{Corpus Approaches to Metaphor}

The central idea that metaphors are building blocks of our conceptual thinking introduced by cognitive linguists exerts great influence on the contemporary understanding of metaphor. Nevertheless, in the light of corpus evidence, some of Lakoff and Johnson's (1980) invented linguistic metaphors can be shown to be unidiomatic or unnatural, since "intuitions are not necessarily explicit and systematic" (Semino, 2008).

Example (4) is a sentence invented by the leading metaphor theorist Zoltán Kövecses (1991) as a supposed realization of the conceptual metaphor HAPPINESS IS LIGHT. When examining the collocation of gleam via the Bank of English, Deignan (2005) notices that there is only one "instance of verbal gleam collocating with eyeleyes and connoting an emotion like happiness". In other words, despite that gleam is significantly collocated with eyes and such a collocation does indicate emotion of some kind, it is not happiness or amusement.

\section{(4) Amusement gleamed in his eyes.}

It might be fair to say that corpus methods, over the past ten years, have established themselves as the major empirical paradigm in linguistic study of metaphor. Unlike investigations of lexical items which can be retrieved directly, using corpus to research metaphor is quite complex and challenging in the sense that conceptual mappings are not linked to particular linguistic forms. As a result, researchers would have to come up with a number of strategies for extracting linguistic expressions manifesting conceptual mappings from corpora.

Stefanowitsch (2006) summarizes seven strategies of extracting metaphors and metonymies from corpora: (i) 
Manual searching; (ii) Searching for source domain vocabulary; (iii) Searching for target domain vocabulary; (iv) Searching for sentences containing lexical items from both the source domain and the target domain; (v) Searching for metaphors based on "markers of metaphor"; (vi) Extraction from a corpus annotated for semantic fields/domains; (vii) Extraction from a corpus annotated for conceptual mappings. The strategy employed in this study is similar to the second one in that we first calculate collocates of inflation and then manually select out the metaphorical collocates from source domains.

\subsection{Corpus and Corpus Analysis Tool}

The corpus used in the study is COCA (Corpus of Contemporary American English) created by Mark Davies of Brigham Young University. COCA contains more than 450 million words of text spanning from 1990 to 2012 and is equally divided among spoken, fiction, popular magazines, newspapers, and academic texts.

The corpus tool used in this study is the Brigham Young University (BYU) online interface, which falls into the category of fourth-generation concordancers. The system was developed by Mark Davies, and, to date, it is probably the most powerful, and most widely used, SQL-based corpus analysis tool (McEnery \& Hardie, 2012). The BYU online interface allows users to search for exact words or phrases, wildcards, lemmas, part of speech, or any combinations of these. One can also search for collocates within a ten-word window (e.g., all nouns, all adjectives, or all verbs near a search word).

\subsection{Corpus Query and Analysis Procedures}

There are four steps in this study. The first step is to generate collocates of inflation in COCA by employing the BYU system. The BYU online interface provides MI (Mutual Information) measure as the only way to calculate the strength of a collocation. A MI-score of 3 or higher can be taken to be significant (Hunston, 2002) and that is probably why the default value is 3 in the BYU system. The optimal span of calculating collocates is $4: 4$, as stated in Sinclair (1991), "Collocation is the cooccurrence of two or more words within a short space of each other in a text. The usual measure of proximity is a maximum of four words intervening". The search item is merely inflation instead of inflations, considering that there are 10658 occurrences of inflation in COCA and only 19 occurrences of inflations, which strongly suggests that inflations might be a misspelling.

Having generated collocates of inflation in COCA sorted by frequency, the next step is to find out metaphor keywords, each of which will then be closely examined by perusing its concordance lines one by one before determining it is used metaphorically or literally. In general, our research follows the practice of metaphor identification procedure suggested by Steen et al. (2010). The Oxford English Dictionary has been frequently referred to when it was hard to identify the source domain of each word under investigation. For instance, halt was labeled by Crawford Camiciottoli (2007) as mechanical metaphor. The investigation of OED, however, indicates that halt was originally an animal's behavior.

The third step is to classify metaphorical collocates into different categories. Grawford Camiciottoli (2007) takes cues from previous studies and compiled lists of items representing five root metaphor commonly found in the discourse of business and economics. Each root metaphor categories contain different numbers of lemmas or headwords, as shown in Table 1. Given the overlapping features among different types of metaphors, it may as well cause problem to the task of assigning certain metaphorical expressions to metaphorical concepts. Significant change has thus been made despite that we based our categorization mainly on Crawford Camiciottoli (2007). When some words cannot be easily classified into a certain category, they were labeled as others. Words like specter, phantom, bugaboo, or evil, fall into this category. Although other words (such as modest, persistent, raise, rage, restrain, scare, ease, quiescent, muted, rob, scourge, lurk, and the like) can be grouped as human being, they do not belong to neither warfare metaphor, nor sports or disease metaphor, and thus are labeled as general under the cover term human being.

Calculating resonance of source domains is the final step. According to Charteris-Black (2004), resonance is the sum of the tokens multiplied by the sum of the types of the metaphors that are from the same source domain. By providing empirical evidence for the resonance of different source domains, the resonance serves as an indication of the extent to which metaphor source domains are found in a particular corpus and therefore is a measure of their productivity. 


\section{Results and Analysis}

Table 1 lists the metaphorical collocates of inflation according to root metaphor category along with their frequencies in parentheses.

Table 1. Specific inflation metaphors in the COCA

\begin{tabular}{ll}
\hline Root & Items \\
\hline Fire & ignite (25), fuel (23), spark (13), dampen (12), stoke (10), kindle (9), choke (4), stifle (2), fan \\
& (2), flare-up (2), douse (1), snuff (1) \\
Liquids & erode (56), surge (44), subside (4), simmers (2), emergence (1), ebb (1), dilute (1), spurt (1), \\
& recede (1), buoy (1) \\
Plant & hedge (44), nip (3) \\
Animal & soar (64), runaway (54), rampant (52), curb (31), tame (23), rein (19), spur (18), creep (10), \\
& whip (10), gallop (9), halt (9), roar (7), hover (3), curtail (1), spawn (1), gnaw (1), hibernation \\
Disease & plague (23), worsen (7), benign (5), virulent (4), debilitate (3), bout (1), chronically (1) \\
Warfare & threat (45), subdue (19), target (11), beat (10), preempt (9), vigilant (8), ravage (6), undermine \\
& (5), forestall (5), counteract (5), eliminate (3), ferocious (3), ruinous (3), clobber (3), buster (2), \\
& eradicate (2), besieged (2), thwart (2), bash (1), beset (1) \\
pace (147), outstrip (11), lag (11), surpass (3), quicken (2), outrun (2), bout (2), best (1), \\
tug-of-war (1), zip (1), overtake (1) \\
accelerate (69), faster (65), control (33), slow (32), trigger (20), skyrocket (17), rapid (13), heat \\
(13), escalate (7), decelerate (3), ratchet (3), unchecked (2), readjusted (1), chug (1), damper \\
(1), zoom (1) \\
low (580), rise (223), high (185), increase (54), reduce (44), decline (36), fall (30), exceed (30), \\
spiral (24), hyper (9), upward (8), uptick (8), downward (6), boost (6), peak (5), diminish (5), \\
upturn (2), hike (2), plummet (2), upswing (1)
\end{tabular}

Lakoff and Johnson (1980) identified three categories of metaphor: orientational, structural and ontological metaphor. An orientational metaphor is a metaphor that involves spatial relationships (such as UP-DOWN, IN-OUT, ON-OFF, and FRONT-BACK). Generally speaking, upward orientation tends to go together with positive evaluation, while downward orientation with a negative one (Kövecses, 2002). Nevertheless, it seems in this study that upward orientation of inflation typically goes together with negative evaluation. Closely related to upward orientation is other metaphorical collocates such as soar and surge which also have negative evaluation.

Orientational metaphor is quite productive, yet organic metaphor is even more productive if we classify plant, animal, human being (including warfare, sports, and disease) into this category, as demonstrated in Table 2. Plant metaphor, however, is quite rare, which is in sharp contrast with the productivity of animal metaphor, warfare metaphor, and sports metaphor.

The literature has underlined frequent references to the economy as a machine or a human being. The recurring networks of organic or mechanistic metaphors in connection with theory-constitutive metaphors in economics have been investigated from a historical perspective (cf., Radman, 1997; Mouton, 2012; Resche, 2012). Inflation metaphors identified in our study, however, mainly fall into the category of organic metaphors whose source domains are either animals or human beings or relevant concept such as disease, as indicated by example (5)-(7):

(5) By the spring of 1922, runaway inflation in Germany was eating into Brassai's income, and the time had come for him to leave. (COCA_1999_MAG_Smithsonian)

(6) You don't have to be a financial whiz to know that rising living costs ravage your savings. Inflation touches everything from the cost of your groceries and gas to medical expenses. (COCA_2008_MAG_U.S. News \& World Report) 
(7) But its statement also made clear that the Fed thinks it has more leeway to cut rates if necessary, in part because inflation has remained dormant. (COCA_2001_NEWS_New York Times)

Table 2. Resonance of each group of metaphor

\begin{tabular}{|c|c|c|c|c|c|}
\hline \multicolumn{3}{|c|}{ Group of Metaphor } & \multirow{2}{*}{$\begin{array}{l}\text { Type } \\
10\end{array}$} & \multirow{2}{*}{$\begin{array}{l}\text { Token } \\
32\end{array}$} & \multirow{2}{*}{$\begin{array}{l}\text { Resonance } \\
320\end{array}$} \\
\hline \multirow{10}{*}{ Organic } & \multicolumn{2}{|l|}{ General } & & & \\
\hline & \multicolumn{2}{|l|}{ Animal } & 17 & 313 & 5321 \\
\hline & \multirow{5}{*}{$\begin{array}{l}\text { Human } \\
\text { Being }\end{array}$} & Warfare & 26 & 151 & 3926 \\
\hline & & Sports & 11 & 182 & 2002 \\
\hline & & Disease & 7 & 44 & 208 \\
\hline & & General & 40 & 114 & 4560 \\
\hline & & Total & 84 & 491 & 41244 \\
\hline & \multicolumn{2}{|l|}{ Plant } & 2 & 47 & 94 \\
\hline & \multicolumn{2}{|l|}{ Others } & 5 & 19 & 95 \\
\hline & \multicolumn{2}{|l|}{ Total } & 118 & 902 & 106436 \\
\hline \multirow{4}{*}{$\begin{array}{l}\text { Natural } \\
\text { Phenomenon }\end{array}$} & \multicolumn{2}{|l|}{ Fire } & 12 & 104 & 1248 \\
\hline & \multicolumn{2}{|l|}{ Liquid } & 10 & 112 & 1120 \\
\hline & \multicolumn{2}{|l|}{ Others } & 5 & 12 & 60 \\
\hline & \multicolumn{2}{|l|}{ Total } & 27 & 228 & 6156 \\
\hline \multicolumn{3}{|l|}{ Mechanical } & 16 & 281 & 4496 \\
\hline \multicolumn{3}{|l|}{ Orientational } & 20 & 1238 & 24760 \\
\hline
\end{tabular}

It is clear that the vivid descriptions as in examples (5)-(7) have given life to inflation by enabling it to eat into people's income, ravage people's savings and touch everything in its sight when it is awake, and to remain inactive when it is dormant. Inflation is not only constructed as a living being, but also metaphorically referred to as other things (such as fire) that may cause harm to the economic and public life. Below are some detailed accounts of several salient types of inflation metaphor.

\subsection{Inflation Is Fire}

Fire is often used as the source domain for some intangible entity. For instance, ANGER IS FIRE (Lakoff, 1987). There is strong corpus evidence that the INFALTION IS FIRE metaphor is quite common. Example (8)-(14) demonstrate how inflation can be sparked, ignited, kindled, fueled, fanned, rekindled or reignited like fire:

(8) The war's primary economic effect was "guns and butter" budgets that helped to spark the inflation of the 1970's and hooked the federal government on deficit spending until the 1990's. (COCA_2000_NEWS_New York Times)

(9) China worries that such rapid growth could ignite inflation, and the country's banking industry has been trying since last year to bring the rate down to 7 percent a year. (COCA_2004_NEWS_Atlanta Journal Constitution)

(10) The sad irony is that the Fed's ability to further loosen credit may be hampered because financial markets fear that tax cuts would increase the deficit and possibly kindle inflation. (COCA_1991_MAG_U.S. News \& World Report)

(11) One risk is that monetary ease is fueling inflation and potential commodity bubbles. (COCA_2011_NEWS_Christian Science Monitor)

(12) But at the same time, new criticisms have surfaced that Mr. Bernanke has fanned inflation and contributed to the decline of the dollar by aggressively cutting interest rates. (COCA_2008_NEWS_New York Times)

(13) Restrictive interest rates made sense in the first half of 2000, when GDP was growing at an annual rate of around 5\%, fast enough to rekindle inflation. (COCA_2001_MAG_Money) 
(14) On Wall Street, some analysts are suggesting that a rise in all sorts of commodity prices could reignite inflation.(COCA_2004_SPOK_NPR_Daybreak)

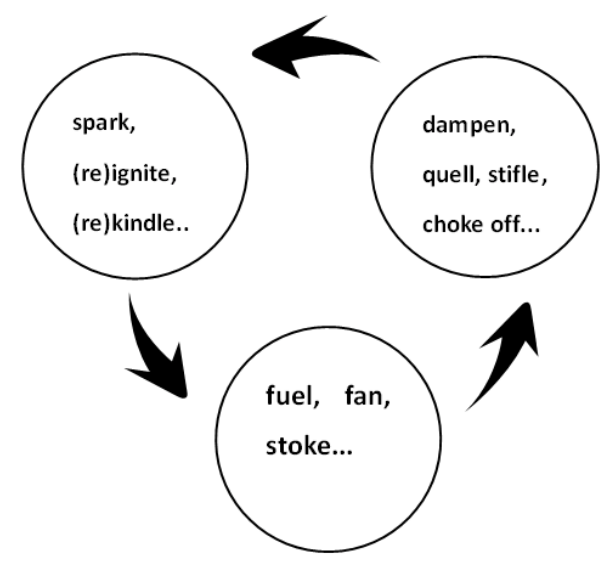

Figure 1. Illustration of metaphor INFLATION IS A FIRE

Fire is a dangerous thing which needs to be dampened, quelled, choked off, or stifled by raising interest rates or other monetary policies as demonstrated in example (15)-(18), which, however, can be rekindled or reignited by circumstances such as fast GDP growth and a rise in commodity prices. In addition, as Figure 1 illustrates, an endless circle is formed under the forces of various external economic factors, which, to some extent, reflects the cyclical nature of economy.

(15) The Federal Reserve will raise interest rates if necessary to dampen inflation, Fed chairman Alan Greenspan told the Senate Banking Committee. (COCA_1996_NEWS_Christian Science Monitor)

(16) But I think, long term, the question remains, with all of this cash being flooded into the U.S. economy - and, really, that means the global economy - it can only but perhaps stoke the fires of inflation longer-term. (COCA_2010_SPOK_PBS NEWSHOUR 6:00 PM EST)

(17) Most economists attribute the jobless increase to a sharp rise in interest rates engineered by then-Federal Reserve Chairman Paul Volcker in an ultimately successful effort to choke off inflation. (COCA_2012_NEWS_Associated Press)

(18) Bond traders feared such a boom could force the Fed to lift the key federal funds rate- the rate banks charge each other on overnight loans-as high as $8 \%$ to stifle inflation. (COCA_1995_NEWS_USA Today)

\subsection{Inflation Is an Animal}

Much of human behavior appears to be "metaphorically understood in terms of animal behavior" (Kövecses, 2002), partly because animals (especially ferocious animals) "serve as prototypes for threats and dangers to mankind" and in turn are "typically employed to construct negative evaluations" (Charteris-Black, 2004). Evidence from COCA indicates that the most salient properties of wild animals as a source domain are mapped onto the abstract and complex target domain, INFLATION, producing various conceptual mappings, which refer to the ways that wild animals move, look, sound, eat/are fed, attack and are controlled.

The INFLATION IS AN ANIMAL metaphor reveals a very complex cognitive structure. To be more specific, example (19) describes inflation as a violent lion or other ferocious animals roaring, example (20) analogizes INFLATION to a greedy predator trying to capture nest egg, and example (21) explicitly refers to INFLATION as a terrible monster, Godzilla, which seems to be out of cage again, and example (22) directly calls INFLATION dragon, which is seen as an evil and fierce animal in Western cultures.

(19) But the evidence from that earlier period is tainted by the fact that inflation was roaring at the time - creating bracket creep, over-taxation of illusory capital gains and paper profits, and rising interest rates. (COCA_1997_MAG_National Review)

(20) This increase in value protects your nest egg from inflation. (COCA_1993_MAG_Consumers Research Magazine)

(21) In fact, people were saying the inflation monster was tamed and now, it seems, Godzilla is back out of the cage. (COCA_1990_SPOK_CNN_NewsSun)

(22) Mrs. Thatcher was widely seen as having slain the dragon of inflation. (COCA_1993_MAG_National Review) 
Given the threats that these animals may pose, measures are taken to curb, rein in, whip, tame and halt the wild animal.

(23) Historians will debate Mr. Reagan's role in curbing inflation. (COCA_2004_SPOK_CNN_SunMorn)

(24) To rein in rampant inflation, Mayorga has already sharply devalued the local currency-the cordoba — crimping illegal trading for the dollar. (COCA_1990_NEWS_Christian Science Monitor)

(25) The man who whipped inflation may have a tougher foe in getting to the bottom of the multimillion-dollar humanitarian deal between the United Nations and the Iraq of Saddam Hussein. (COCA_2004_SPOK_CNN_Dobbs)

(26) Taming inflation in the early 1980 s was the key to ushering in the glorious prosperity we've enjoyed ever since. (COCA_1998_MAG_Fortune)

(27) Those reforms, engineered by former Prime Minister Yegor Gaidar, lifted state price controls in many economic spheres, spurring massive inflation that is still running between 20 and 30 percent monthly. (COCA_1993_NEWS_Christian Science Monitor)

(28) In constant dollars, despite the galloping inflation of that decade, it rose more than 12 percent. (COCA_1995_MAG_American Heritage)

A close examination of these verbs and the adjective galloping may give us the impression that there is a more concrete and sub-level metaphor: INFLATION IS A HORSE, as the first two collocates of galloping are horse and horses, and the strongest concrete noun collocate and the fourth strongest noun collocate of rein in is horse as well. This metaphor is motivated by a series of actions aiming to keep under control a wild horse and remind people of the traditional practice of taming a horse.

\subsection{Inflation Is an Enemy}

Warfare metaphor plays a central part in human life. In view of the downside effects of inflation, it is not surprising to find a large number of evidences pointing to the more concrete metaphor INFLATION IS AN ENEMY, which is in line with the metaphoric theme of fighting and warfare.

As an enemy, inflation seems to have the power to cripple one's presidency (example 29), to rip a country (example 30), and to besiege the public (example 31), to hurt payments (example 32), and to injure certain classes (example 33):

(29) But his presidency was crippled by inflation and the energy crisis. (COCA_1994_NEWS_Atlanta Journal Constitution)

(30) Since no real economic production supports the currency, Yugoslavia is ripped by runaway inflation that threatens to match the disastrous situation in Germany in the 1920s when citizens had to carry their grocery money in baskets. (COCA_1993_MAG_Christian Century)

(31) Remember those terrible days of the 1970s and early 1980s — when we were besieged with double-digit inflation and interest rates? (COCA_1998_MAG_Fortune)

(32) Even 3\% inflation will hurt fixed payments eventually. (COCA_2007_MAG_USA Today)

(33) The system soon inflates, and the classes which installed the populist are injured by the inflation and the collapse of growth. (COCA_1991_ACAD_Journal of Interamerican Studies \& World Affairs)

Since inflation is an enemy, it has to be fight against by using both weapons and tactics. Normally, it is the central bank (for example, the Federal Reserve System in America, or Fed in short) that wages the war, and the monetary policy is the main weapon as illustrated by example (35)-(37). But it could also be up to the public to combat inflation by employing some instruments such as the bike (example 38 ).

(34) It's very clear that they were preemptively attacking inflation before it showed up in the hope of sustaining the business expansion. (COCA_1996_SPOK_PBS_Newshour)

(35) In the early' $80 \mathrm{~s}$, the Fed waged a ferocious battle against inflation by keeping interest rates high enough to first plunge the economy into recession and then to keep it from overheating. (COCA_1995_NEWS_USA Today)

(36) Jasinowski and others argue that the Fed is using old tactics to fight a formerly ferocious enemy, inflation, that is substantially weakened and nowhere in sight. (COCA_1995_SPOK_PBS_Newshour)

(37) From the outset, we strongly agreed on the need to tighten monetary policy as the main weapon against inflation, which was running at double digits at the beginning of the Reagan Administration. (COCA_2011_MAG_USA Today)

(38) The bike was becoming something almost indispensable, a utilitarian piece of everyday middle-class weaponry meant to combat fuel-price inflation.(COCA_2009_MAG_Bicycling) 
If the outcome of the war against inflation is positive, then it is a victory (example 39) and accordingly inflation yielded (example 40).

(39) Federal Reserve Chairman Alan Greenspan has hinted that he is not yet ready to declare victory over inflation and will remain vigilant. (COCA_1995_MAG_U.S. News \& World Report)

(40) As inflation yielded to tight monetary policy in the early 1980s, public confidence returned. (COCA_1992_MAG_USA Today)

\subsection{Inflation Is Disease}

The INFALTION IS DISEASE metaphor, which is reminiscent of THE ECONOMY IS A PATIENT (Charteris-Black, 2000), motivates metaphorical expressions relating to the breakout, diagnosis, and treatment of the economic ailment. Disease can be not that serious, as exemplified in the adjective benign, or be as rampant and virulent as a plague.

(41) In addition, unemployment and inflation continued to plague the economy. (COCA_2006_ACAD_International Social Science Review)

(42) Hungary's economy is in serious disrepair, debt a burden, inflation a plague, unemployment a prospect. (COCA_1990_SPOK_PBS_Newshour)

(43) Once again $a$ bout of inflation threatens to disrupt the economy. (COCA_1994_MAG_National Review)

(44) As long as the economy keeps doing what it's been doing, as long as interest rates stay low, and inflation stays benign, we don't think that anything terribly traumatic can happen short term in the market. (COCA_1998_NEWS_Denver Post)

(45) His list of the country's economic ailments referred to slow economic growth, persistent unemployment, virulent inflation, wide gaps in incomes and wealth. (COCA_2007_ACAD_Journal of International Affairs)

A disease has to be treated (example 46) or remedied (example 47-48) before it worsens:

(46) Conventional treatments of inflation assume that banks, as a net creditor sector, oppose inflation because it hurts their bottom line. (COCA_1996_ACAD_Latin American Research Review)

(47) Where there has been excessive growth in the supply of money and therefore inflation, the appropriate remedy is monetary restraint and (temporarily) high unemployment rates. (COCA_1990_ACAD_Theological Studies)

(48) The heterodox plan aimed at remedying two ills simultaneously: inflation and balance of payments deficits. (COCA_1994_ACAD_Studies in Comparative International Development)

If appropriate treatment or remedy—most likely monetary restraint implemented by the Federal Reserve Board-is taken, inflation can be cured very quickly:

(49) Inflation can be cured overnight with high interest rates. (COCA_2002_NEWS_Washington Post)

\subsection{Inflation Is a Racer}

This metaphor overlaps to some extent with both INFLATION IS AN ANIMAL and INFLATION IS AN ENEMY. It is arguably a distinct category, however, which can be classified into sports metaphor. The cognitive structure of this metaphor involves in the process of heading forward on the part of INFLATION and other economic performance indicators, such as prices, wage(s), stock value and interest rates. Taking INFLATION as the reference point as illustrated in Figure 2, its rivals may lag behind, keep pace with or outpace INFLATION.

(50) In effect, inflation is running at rates that are too low relative to the level that the committee judges to be more. (COCA_2010_SPOK_PBS_NewsHour)

(51) But the unemployment rate jumped from $4.7 \%$ to $5 \%$ in December, and wages lagged behind inflation. (COCA_2008_NEWS_USA Today) 


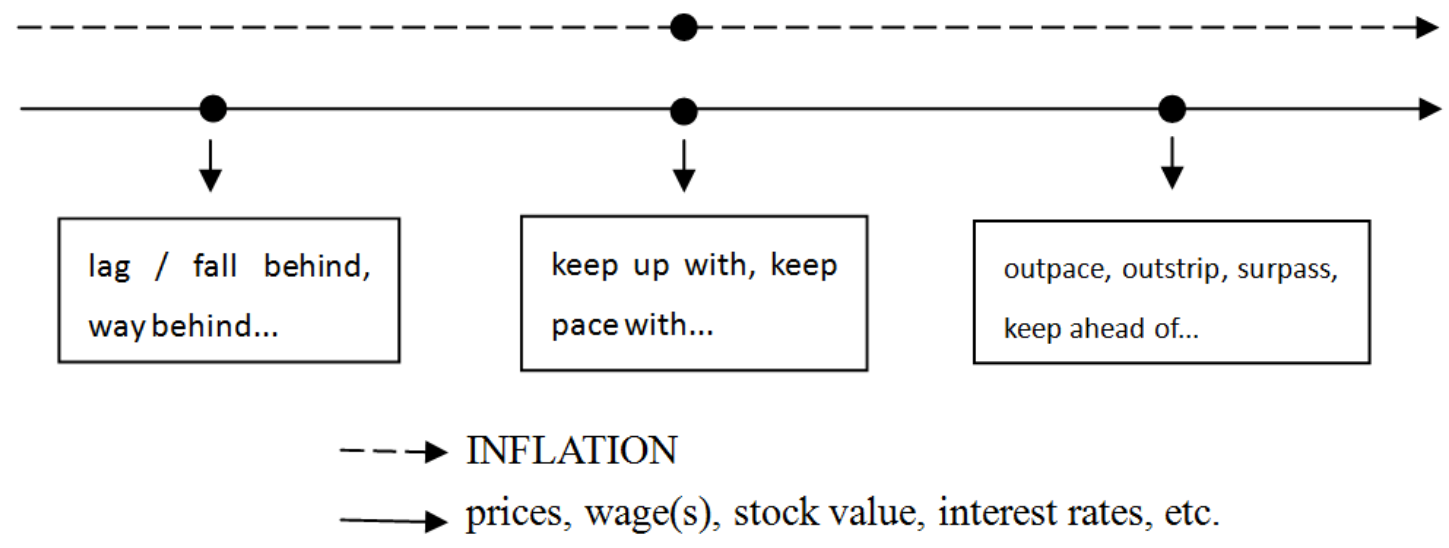

Figure 2. Illustration of metaphor INFLATION IS A RACER

If inflation wins the race, the consequences can be really serious, for it erodes or eats up/away at the future value of the dollar, fixed payments, bonds' value, the value of their savings, the real value of their liabilities and other kinds of values (see the following concordance lines). Therefore, it is necessary to keep pace with inflation (example 52), or even outpace, outstrip, surpass, and keep dividends ahead of inflation (example 53-56):

(52) The Illinois senator promised to raise the minimum wage to keep pace with inflation. (COCA_2008_NEWS_Houston Chronicle)

(53) In general the value of stocks has risen by an average of about $10 \%$ a year, fast enough to outpace the rate of inflation. (COCA_1993_MAG_Consumers Research Magazine)

(54) From 1987 through 1995, South Korean wages rose by an average of 15 percent a year, far outstripping inflation and gains in productivity. (COCA_1997_NEWS_Washington Post)

(55) But as increases in college tuition surpass the rate of inflation each year and as competition escalates for a limited pool of grant money, students are depending more on loans regardless of whether they pick an Ivy League school or public college. (COCA_1996_NEWS_Associated Press)

(56) The companies regularly raise dividends, keeping them ahead of inflation. (COCA_1991_MAG_Money)

\subsection{Inflation Is a Machine}

Apart from entities or phenomena related to organisms and nature, inflation can also be metaphorically described as a machine, and for the most part, a vehicle, whose various states of motion are fully represented in the INFLATION IS A MACHINE metaphor. To be specific, this machine can be triggered by a certain condition (example 57), then it may chug along at a certain rate (example 58), accelerate or ratchet up, decelerate or slow, or even stop (example 59-62):

(57) Analysts are concerned that rising gas prices may cut into consumer spending and trigger inflation. (COCA_2012_CBS_SPOK_NewsMorn)

(58) Since the 1960s, though, inflation has chugged along at an annual average rate of 5\% - fast enough to halve the purchasing power of your principal every 14 years. (COCA_1991_MAG_Money)

(59) According to this report, the vast majority of Americans are seeing their wage gains evaporate because of accelerating inflation. (COCA_2006_NPR_SPOK_Daybreak)

(60) There are a few market sectors, however, that actually benefit when inflation starts ratcheting up. (COCA_1994_MAG_Money)

(61) Although inflation decelerated rapidly, it did not stop. (COCA_1997_ACAD_Latin American Research Review)

(62) Retail sales in the U.S. picked up in September, even as inflation slowed. (COCA_2010_SPOK_PBS NEWSHOUR 6:00 PM EST)

However, machine cannot always operate smoothly by itself since it may malfunction (heat up in example 63) or even run out of control (example 64). In such cases, measures should be taken by the governments or central banks to cool it down, keep it on its downward track, or keep it in check or under control (example 65-68).

(63) Despite a growth surge in the second quarter, the economy is still giving off mixed signals and no clear sign of inflation heating up, they say. (COCA_1996_NEWS_Christian Science Monitor)

(64) But neither did it confirm the Keynesian view that wide-open deficit spending would lead to uncontrolled inflation. (COCA_1991_NEWS_New York Times) 
(65) Germany, Europe's strongest economy, faced with the huge cost of reunification, had raised interest rates to slow the economy and cool inflation. (COCA_1992_SPOK_ABC_Business)

(66) However, progress is difficult when government spending is heavily dependent on foreign aid and investment must be curbed to keep inflation on its downward track. (COCA_2010_ACAD_Foreign Policy)

(67) Investors were hoping for signals that rates have been raised enough to keep inflation in check. (COCA_2006_NEWS_Associated Press)

(68) One of the chief reasons: the Federal Reserve's 17 consecutive interest-rate hikes in an effort to keep inflation under control. (COCA_2006_NEWS_Denver Post)

\section{Discussion}

So far we have identified, based on corpus data, a number of main types of inflation metaphor: INFLATION IS FIRE, INFLATION IS DISEASE, INFLATION IS AN ANIMAL, INFLATION IS AN ENEMY, INFLATION IS A RACER and INFLATION IS A MACHINE. The diversified metaphor types indicate that metaphorical structuring is partial and one can apply multiple metaphors to a single concept to highlight different aspects of it, the so-called principle of "metaphorical highlighting" (Kövecses, 2002). Attributing animate features to the inanimate concept inflation "not only gives us a very specific way of thinking about inflation but also a way of acting toward it" (Lakoff \& Johnson, 1980). The salient properties of wild animals, such as being dangerous, violent, cruel, fierce, savage, speedy, or untamed, are mapped onto inflation to depict its detrimental effect on currency, people and their savings, and a country's economy in general (cf., also Silaski \& Durovic, 2010).

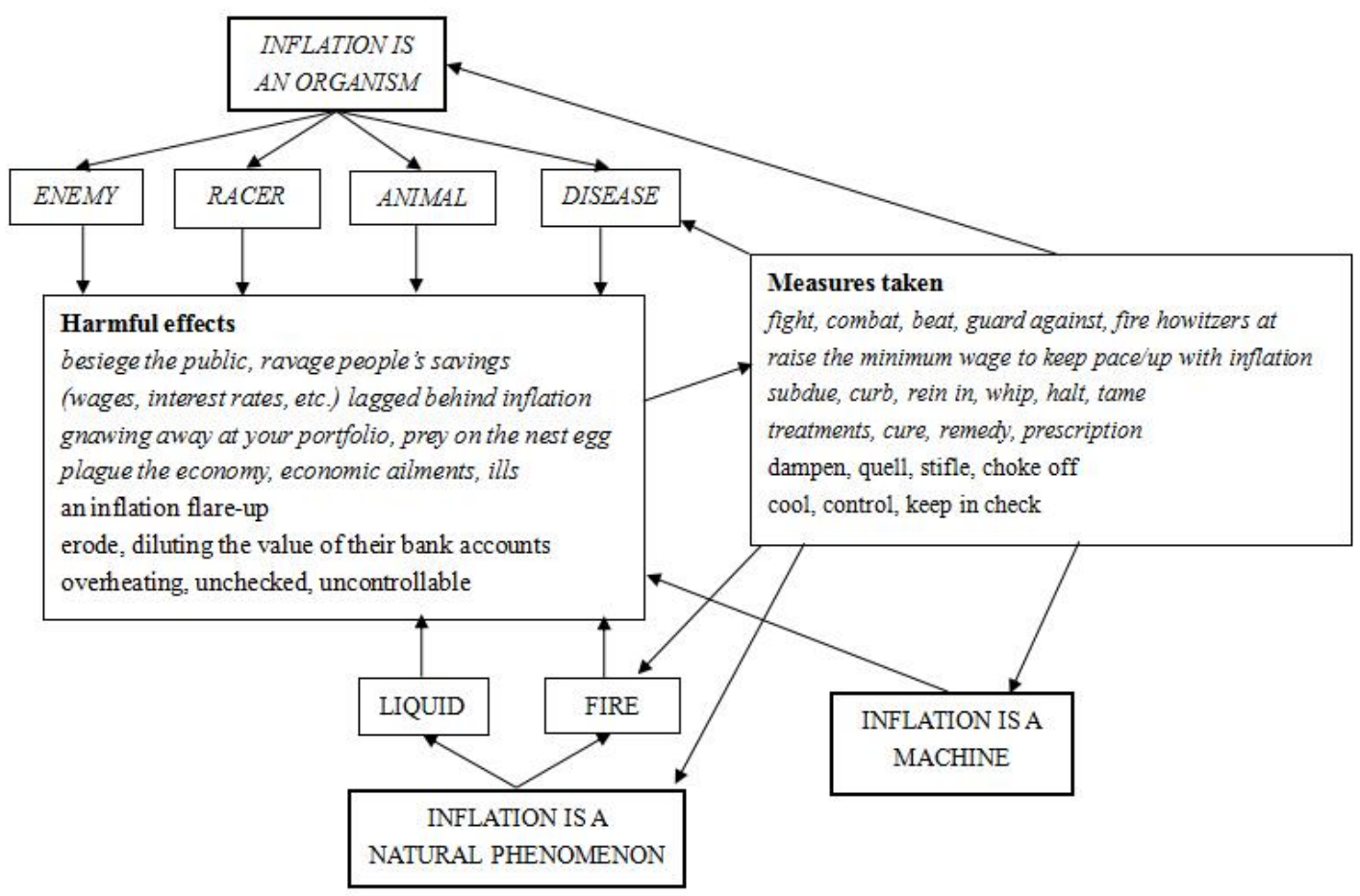

Figure 3. The network of inflation metaphor

On the other hand, we can also find some common ground for the variety of inflation metaphors. No matter how the source domain FIRE, DISEASE, ANIMAL or ENEMY appears differently, they all call for some kind of control over the dangerous thing, which, if left uncontrolled, may cause serious harm or damage to people around and the society at large. Thus, the conceptual basis for inflation metaphor is the semantic transfer of the most salient attributes that are stereotypically associated with the dangerous things to refer to inflation and its harmful effects. Accordingly, governments and central banks have to take some measures to control inflation. Figure 3 illustrates this point showing the metaphorical networks used when dealing with the risks to the economy.

It is evident that our thinking of inflation is metaphorical by nature. We borrow ideas from the domain of fire or war that seems familiar to us and project them to the more abstract and elusive domain of inflation so that we can 
become alert to the danger or potential harmful effect of inflation. Nevertheless, the metaphorical use is not without its problem. Each time we use a metaphor to understand a concept it highlights certain aspects of the concept and hides others. Inflation, seen as dangerous creature or dangerous thing, highlights its potential harm to economy, but it hides its likely positive effects to stimulate economy when inflation rate is below 3 percent. A basic principle in modern macroeconomics is that there is a tradeoff between inflation and unemployment (Mankiw, 2010). The lower inflation rate is likely to stimulate the economy and thus reduce the rate of unemployment. An interesting question then arises: why is inflation, based on the corpus evidence, regarded as something dangerous? One reason is that inflation does cause harm to economy as summarized in example (69):

(69) Inflation is rampant for the first time since the 1970s. This undermines the economy in many ways. It artificially boosts capital gains tax rates because even inflated gains are taxed. It distorts prices and sends out confusing signals to producers and consumers. Finally, it drives up the cost of living faster than wage rates and undermines consumer confidence. (COCA_2008_MAG_American Spectator)

Even the founder of macroeconomics John Maynard Keynes warned the western people of the sinister nature of inflation, "Lenin is said to have declared that the best way to destroy the Capitalist System was to debauch the currency. Lenin was certainly right. There is no subtler, no surer means of overturning the existing basis of society than to debauch the currency. The process engages all the hidden forces of economic law on the side of destruction, and does it in a manner which not one man in a million is able to diagnose" (Mankiw, 2010).

Another reason lies in the fact that it might be easy to control inflation (example 70) when inflation rate is low, but when it arises to 10 percent it may become totally out of control (example 71). This explains why in the 1970s, Presidents Richard Nixon, Gerald Ford, and Jimmy Carter all wrestled with a rising rate of inflation, and why inflation is one of primary concerns of economists and policymakers.

(70) Wholesale prices fell sharply in August, the Labor Department said in a report suggesting that inflation remains tame and the economy is not in serious danger of overheating. (COCA_1998_NEWS_Christian Science Monitor)

(71) You can have stable 2 to 3 percent inflation. But you can't have stable 10 percent inflation. When everybody assumes 10 percent, all the forces that produced 10 percent push it to 20 percent, and then 40 percent, and soon people are lugging currency in a wheelbarrow, as in the famous photos from Weimar Germany. Thirty years ago, we peered into this abyss and pulled back just in time. (COCA_2010_MAG_The Atlantic Monthly, 2010)

\section{Conclusion}

The human conceptual system is heavily metaphorical in nature and we use metaphors spontaneously and with ease in the course of everyday communication (Lakoff \& Johnson, 1999). This paper has shown how inflation, an abstract concept and a normal economic phenomenon, is typically understood and explained in metaphoric terms by examining a big contemporary corpus.

This study has a number of pedagogical implications. First, a better knowledge about inflation metaphors can help economics students understand the nature of the inflation concept and the metaphorical nature of economic activities. Since metaphorical expressions in our language are tied to metaphorical concepts in a systematic way, we can use metaphorical linguistic expressions to study the nature of metaphorical concepts and to gain an understanding of the metaphorical nature of our activities (Lakoff \& Johnson, 1980). This study has demonstrated how the abstract concept inflation is made tangible and given meaning through the use of vivid metaphorical expressions.

Second, findings of this study have pedagogical implications for second language learning of relevant words and phrases. Cameron and Low (1999) argues that metaphor is crucial to performance in language and to acquiring a language. An enhanced metaphoric awareness on the part of language learners may be beneficial in recognizing the inference patterns associated with given figurative expressions and remembering unfamiliar figurative expressions (Boers, 2000). Thus, if foreign language learners grasp the inferential structure of the inflation concept, which is accompanied by a rich and coherent lexical field, their ability to recognize, memorize, and even utilize such structures in the context of economics may be greatly improved. And a mastery of inferential structure plus a reasonable number of the lexical items utilized to realize these metaphors would equally enable foreign language learners to understand, memorize and use the metaphorical expressions by taking advantage of the relational or inter-connected vocabulary structures, and hopefully, to create novel figurative expressions concerning inflation and many other similar concepts in their own writing and speaking. Of course, pedagogical processing is necessary when applying what is extracted from corpus into the classroom practice (cf., Cameron, 2003). 
Last but not least, metaphor awareness is also a pedagogical asset for ESP (English for Specific Purposes) teachers, who, though more than likely a non specialist in economics, can grasp from the know-how of his or her own field the crucial role language plays for the discipline and transmit this advantage to students (Roche, 2012). Metaphor can be viewed as a useful teaching device; as a central organizing principle of all language; as a way of viewing and constructing new problems; as a fundamental basis for argument and storytelling.

This study is not without its problems. Mouton (2012) once wisely pointed out, "an adequate analysis of any given economic metaphor should pay proper attention to its historical situatedness". Future research in inflation metaphor can be investigated in more historical context by examining diachronic corpora (such as COHA). It is also insightful to conduct similar research in other languages, including Chinese, in order to verify whether the conceptual mappings and their linguistic instantiations found in the variety of metaphor (i.e., INFLATION IS FIRE, DIESEASE, AN ANIMAL, AN ENEMY, A RACER, A MACHINE) in English are shared by the speakers of other languages. The cross-cultural investigation may as well shed new lights on the causes, processes, and effects of inflation.

\section{Acknowledgements}

This study is a part of the research projects 1) the Project of Humanity and Social Sciences Key Research Base approved by the Ministry of Education of China (13JJD740005); and 2) the 2012 Project of the Twelfth Five-Year Plan of Guangdong Social Sciences (GD12XWW04) sponsored by Guangdong Social Science Foundation.

\section{References}

Alejo, R. (2010). Where does the money go? An analysis of the container metaphor in economics: The market and the economy. Journal of Pragmatics, 42, 1137-1150.

Aristotle. (2002). On Poetics (1st ed.). Augustine's Press.

Aristotle. (2007). On Rhetoric: A Theory of Civic Discourse (2nd ed.). Oxford: Oxford University Press.

Berber Sardinha, T. (2012). Metaphors of the Brazilian Economy from 1964 to 2010. In H. Herrera-Soler, \& M. White (Eds.), Metaphor and Mills: Figurative Language in Business and Economics (pp. 103-126). Berlin: De Gruyter Mouton.

Boers, F. (2000). Enhancing metaphoric awareness in specialized reading. English for Specific Purposes, 19(2), 137-147. http://dx.doi.org/10.1016/S0889-4906(98)00017-9

Boyed, R. (1993). Metaphor and theory change: What is a metaphor for? In A. Ortony (Ed.), Metaphor and thought (pp. 481-532). Cambridge: Cambridge University Press.

Cameron, L. (2003). Metaphor in Educational Discourse. London: Continuum.

Cameron, L., \& Deignan, A. (2003). Using large and small corpora to investigate tuning devices around metaphor in spoken discourse. Metaphor and Symbol, 18, 149-160.

Cameron, L., \& Low, G. (1999). Metaphor Language Teaching, 32, 77-96.

Charteris-Black, J. (2004). Corpus Approaches to Critical Metaphor Analysis. Basingstoke, England: Palgrave Macmillan. http://dx.doi.org/10.1057/9780230000612

Charteris-Black, J. (2000). Metaphor and vocabulary teaching in ESP economics. English for Specific Purposes, 19(2), 149-165. http://dx.doi.org/10.1016/S0889-4906(98)00025-8

Charteris-Black, J., \& Ennis, T. (2001). A comparative study of metaphor in Spanish and English financial reporting. English for Specific Purposes, 20, 249-266. http://dx.doi.org/10.1016/S0889-4906(00)00009-0

Charteris-Blacka, J., \& Musolff, A. (2003). "Battered hero" or "innocent victim"? A comparative study of metaphors for euro trading in British and German financial reporting. English for Specific Purposes, 22(2), 153-176. http://dx.doi.org/10.1016/S0889-4906(02)00012-1

Crawford Camiciottoli, B. (2007). The Language of Business Studies Lectures. John Benjamins B.V.

Henderson, W. (1982). Metaphor in economics. Economics, 18, 147-153.

Henderson, W. (1994). Metaphor and economics. In R. E. Backhouse (Ed.), New Directions in Economic Methodology (pp. 343-367). London: Routledge.

Henderson, W. (2000). Metaphor, economics and ESP: Some comments. English for Specific Purposes, 19(2), 161-173. http://dx.doi.org/10.1016/S0889-4906(99)00035-6 
Henderson, W. (2006). Evaluating Adam Smith: Creating the Wealth of Nations. London: Routledge.

Henderson, W., \& Dudley-Evans, T. (1990). Introduction: The analysis of economics discourse. In T. Dudley-Evans, \& W. Henderson (Eds.), The language of economics: The analysis of economics discourse (pp. 2-15). London: MEP/British Council.

Henderson, W., \& Hewings, A. (1990). A language of model building? In T. Dudley-Evans, \& W. Henderson (Eds.), The language of economics: The analysis of economics discourse (pp. 43-54). London: MEP/British Council.

Hu, C. (2014). A Corpus-based analysis of bubble metaphor in economics. Journal of PLA University of Foreign Language, 1, 18-31.

Hunston, S. (2002). Corpora in Applied Linguistics. Cambridge: Cambridge University Press.

Jeffreys, D. (1982). Metaphor in economics—An illustrative appendix. Economics, 18(4), 154-157.

Klamer, A., \& McCloskey, D. N. (1992). Accounting as the Master Metaphor of Economics. The European Accounting Review, 1, 145-160. http://dx.doi.org/10.1080/09638189200000008

Kövecses, Z. (1991). Happiness: A definitional effort. Metaphor and Symbolic Activity, 6, 29-46. $\mathrm{http}: / / \mathrm{dx}$. doi.org/10.1207/s15327868ms0601_2

Kövecses, Z. (2002). Metaphor: A Practical Introduction. Oxford: Oxford University Press.

Lakoff, G. (1987). Women, Fire, and Dangerous Things: What Categories Reveal About the Mind. Chicago: The University of Chicago Press.

Lakoff, G. (1993). The contemporary theory of metaphor. In A. Ortony (Ed.), Metaphor and Thought (2nd ed., pp. 202-251). Cambridge: Cambridge University Press.

Lakoff, G., \& Johnson, M. (1980). Metaphors we live by. Chicago: University of Chicago Press.

Lakoff, G., \& Johnson, M. (1999). Philosophy in the Flesh: The Embodied Mind and its Challenge to Western Thought. New York: Basic Books.

Mankiw, N. G. (2010). Macroeconomics (7th ed.). Worth Publishers.

McCloskey, D. N. (1990). If you're so smart: The narrative of economic expertise. Chicago: University of Chicago Press.

McCloskey, D. N. (1995). Metaphors Economists Live by. Social Research, 62(2), 215-227.

McCloskey, D. N. (1985). The rhetoric of economics. Madison: The University of Wisconsin Press.

Mirowski, P. (1994). Natural Images in Economical Thoughts. Cambridge: Cambridge University Press.

Mouton, N. T. O. (2012). Metaphor and economic thought: A historical perspective. In H. Herrera-Soler, \& M. White (Eds.), Metaphor and Mills: Figurative Language in Business and Economics (pp. 49-76). Berlin: De Gruyter Mouton. http://dx.doi.org/10.1515/9783110274585.49

Radman, Z. (1997). Metaphors: Figures of the Mind. Dordrecht/Boston/London: Kluwer Academic Publishers. http://dx.doi.org/10.1007/978-94-017-2254-4

Resche, C. (2012). Towards a better understanding of metaphorical networks in the language of economics: The importance of theory-constitutive metaphors. In H. Herrera-Soler, \& M. White (Eds.), Metaphor and Mills: Figurative Language in Business and Economics (pp. 77-102). Berlin: De Gruyter Mouton. http://dx.doi.org/10.1515/9783110274585.77

Samuels, W. J. (Ed.). (1990). Economics as Discourse: An Analysis of the Language of Economists. Boston: Kluwer. http://dx.doi.org/10.1007/978-94-017-1377-1

Samuelson, P. A., \& Nordhaus, W. D. (2010). Economics. McGraw-Hill Higher Education.

Semino, E. (2008). Metaphor in Discourse. Cambridge: Cambridge University Press.

Semino, E. (2002). A sturdy baby or a derailing train? Metaphorical representations of the euro in British and Italian newspapers. Text, 22(1), 107-139. http://dx.doi.org/10.1515/text.2002.001

Silaski, N., \& Durovic, T. (2010). CATCHING INFLATION BY THE TAIL: Animal metaphoric imagery in the conceptualisation of INFLATION in English. Ibérica, 20, 57-80.

Sinclair, J. (1991). Corpus, Concordance, Collocation. Oxford University Press. 
Smith, G. (1995). How high can a dead cat bounce? Metaphor and the Hong Kong Stock Market. Hong Kong Papers in Linguistics and Language Teaching, 18, 43-57.

Stefanowitsch, A. (2006). Corpus-based approaches to metaphor and metonymy. In A. Stefanowitsch, \& S. Gries (Eds.), Corpus-Based Approaches to Metaphor and Metonymy (pp. 1-16). Berlin: Mouton de Gruyter. http://dx.doi.org/10.1515/9783110199895

Steen, G. J., Aletta, G., Dorst, J., Berenike, H., Anna, A. K., Tina, K., \& Trijntje, P. (2010). A Method for Linguistic Metaphor Identification: From MIP to MIPVU. Amsterdam: Benjamins.

White, M. (2003). Metaphor and economics: The case of growth. English for Specific Purposes, 22(2), 131-151. http://dx.doi.org/10.1016/S0889-4906(02)00006-6

\section{Copyrights}

Copyright for this article is retained by the author(s), with first publication rights granted to the journal.

This is an open-access article distributed under the terms and conditions of the Creative Commons Attribution license (http://creativecommons.org/licenses/by/3.0/). 